\title{
Determination of water environment standards based on water quality criteria in China: Limitations and feasibilities
}

\author{
Tieyu Wang ${ }^{1,2, *}$, Yunqiao $\mathrm{Zhou}^{1,2}$, Cencen $\mathrm{Bi}^{1}$, Yonglong $\mathrm{Lu}^{1,2}$, Guizhen $\mathrm{He}^{1,2}$, John P. Giesy \\ 1. State Key Laboratory of Urban and Regional Ecology, Research Center for Eco-Environmental Sciences, Chinese Academy of Sciences, \\ Beijing 100085, China \\ 2. University of Chinese Academy of Sciences, Beijing 100049, China \\ 3. Toxicology Centre and Department of Veterinary Biomedical Sciences, University of Saskatchewan, Saskatoon, Saskatchewan, Canada
}

\section{A R T I C L E I N F O}

\section{Article history:}

Received 17 August 2016

Revised 2 November 2016

Accepted 10 November 2016

Available online 1 December 2016

Keywords:

Water quality

Environmental criteria

Standards

Regulations

\begin{abstract}
A B S T R A T
There is a need to formulate water environment standards (WESs) from the current water quality criteria (WQC) in China. To this end, we briefly summarize typical mechanisms applied in several countries with longer histories of developing WESs, and three limitations to formulating WESs in China were identified. After analyzing the feasibility factors including economic development, scientific support capability and environmental policies, we realized that China is still not ready for a complete change from its current nation-wide unified WES system to a local-standard-based system. Thus, we proposed a framework for transformation from WQC to WESs in China. The framework consists of three parts, including responsibilities, processes and policies. The responsibilities include research authorization, development of guidelines, and collection of information, at both national and local levels; the processes include four steps and an impact factor system to establish water quality standards; and the policies include seven specific proposals.

(C) 2016 The Research Center for Eco-Environmental Sciences, Chinese Academy of Sciences.
\end{abstract}

Published by Elsevier B.V.

\section{Introduction}

Water quality criteria (WQC) are the basis of water environment standards (WESs) established to protect humans from water pollution, sustain the productivity of natural resources, and ensure the esthetic quality of the environment (Russo, 2002). Traditionally, WQC have been established based on available data from the 1900s to the 1970s on pollutant toxicity toward aquatic organisms and species (Stephan, 2002) and defined as the maximum dose or concentration of pollutants that might cause adverse or harmful effects to humans or aquatic organisms in the aquatic environment (Chèvre et al., 2006; Deland, 1979). In China, WESs are legal limits that are released by the state administrative departments with consideration of WQC as well as natural, social, economic, and technological conditions and other factors (Meng et al., 2006, 2009). China manages water quality according to its WESs as well as water environment capacity, pollutant discharge, and monitoring methods. However, almost all of these standards were derived from and/or based on WESs or quality criteria of other countries. Considering that the geographic, regional, eco-environmental and socio-economic characteristics of China are quite different from those of the developed countries, the standards or criteria established in those countries do not necessarily or fully meet the current needs for environmental management in China (Fu et al., 2007). Therefore, it is necessary for China to establish more scientifically sound and appropriate WESs based on its own WQC (Feng et al., 2012; Jin et al., 2014; Wang et al., 2016; Yang et al., 2012). In fact, Chinese scientists have already

\footnotetext{
* Corresponding author. E-mail: wangty@rcees.ac.cn (Tieyu Wang).
} 
conducted a substantial amount of researches on water quality (Wang et al., 2013; Zhang et al., 1998). The site-specific WQC for Tai Lake were recently established (Chen et al., 2016) and more criteria are on the way (Yan et al., 2015). In addition, a national strategy for the next 15 to 20 years has been initiated to establish an entire WQC system, based on the regional features and current conditions, and more case studies on environmental quality criteria are being conducted (Wu et al., 2010).

Environmental standards are the scientific basis for implementation of environmental management at the national level. With rapid development of the economy, industrialization, agricultural production and urbanization, environment contamination has widely emerged (Wang and Hao, 2012; Zhang et al., 2013), forcing both the government and scientists to realize the importance of deriving a more scientifically sound WES system from the national WQC according to regional eco-environmental and socio-economic characteristics and regulatory needs. However, little thought has been given to approaches for transforming WQC into WESs in China. In the present study, three limitations in the current system used in China for formulating WESs from WQC are discussed. A comparison of management strategy for surface water quality in China and several other countries or regions was introduced. We have also proposed a framework for transforming WQC into WESs for use in China. In this framework, we have considered functional responsibilities, analyzed the proposed transformation process and outlined needs for policies to make the proposed WESs effective within the current and future social system in China. Finally, this information was applied to develop proposed science-based WESs to achieve reasonable protection and management for aquatic resources in China.

\section{Mechanisms for formulating WESs from WQC in the developed countries}

\subsection{USA}

Scientists in the United States (USA) have been conducting research on WQC since the 1950s (Kassem et al., 1969; Shaw and Grushkin, 1957). The Clean Water Act (CWA, 1972) established basic structures for regulating discharges of pollutants into waters in the USA and deriving quality standards for surface waters. Under the requirements of the CWA, the US Environmental Protection Agency (US EPA) is responsible for developing WQC based on the latest scientific knowledge and processes for deriving WESs (Fig. 1). States and tribes are responsible for establishing their own WESs by: (1) directly adopting the recommended national WQC; (2) modifying the recommended national WQC to reflect site-specific conditions or (3) adopting criteria based on other scientifically defensible methods. Moreover, states and tribes are required to organize public hearings for the purpose of revising applicable WESs periodically and submitting WESs to the US EPA for authorization at least once every 3 years. Otherwise, the WESs cannot be applied without approval of the US EPA.

\subsection{Australia}

Unlike the United States, there are no mandatory WESs in Australia. Instead, water quality targets are used as WESs in the National Water Quality Management Strategy (NWQMS) and WQC are given as the national water quality guidelines. The NWQMS uses environmental values to describe particular environments which are important for ecosystem health or public benefit, welfare, safety and health that need to be protected from pollution, waste discharge and disposal. A threetiered approach for water quality management is outlined as follows (Fig. 2): (1) At the national level - Sustainable utilization of water resources and coordinated development of the economy and society should be achieved by protecting and improving water quality. The administrative department should simultaneously establish the national criteria for the acceptable level of environmental water quality; (2) At the state or territory level State water quality planning and environmental policy processes should be implemented, and a management framework including water quality goals based on national criteria should be provided; (3) At the regional or watershed level - Relevant stakeholders are encouraged to participate in establishing and implementing watershed management strategies to revise relevant water quality plans, and regional communities are encouraged to participate in identifying the local environmental

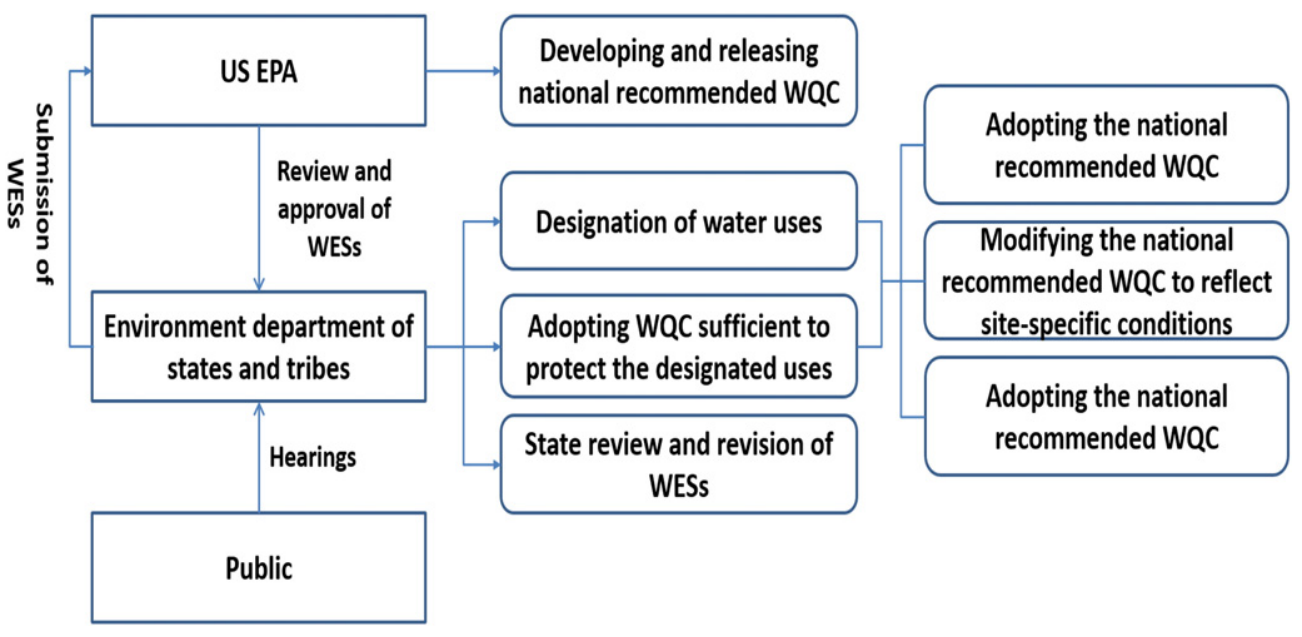

Fig. 1 - Mechanisms for deriving WESs from WQC in USA. WESs: water environment standards; WQC: water quality criteria. 


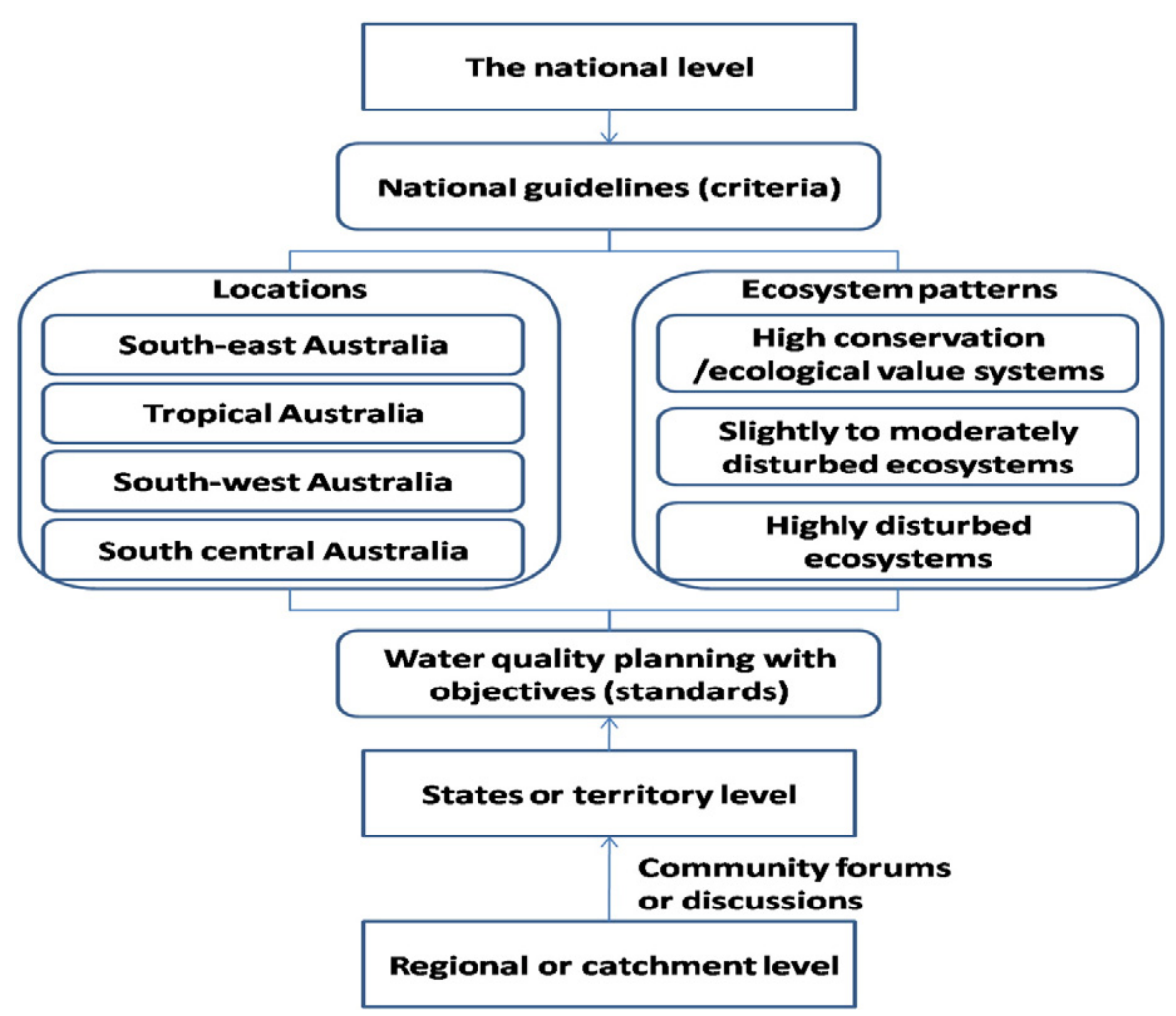

Fig. 2 - National water quality management strategies in Australia.

values and to monitor and report the progress and performance of the plans.

\subsection{European Union}

The European Parliament and Council established the Water Framework Directive (WFD, 2000/60/EC) on October 23, 2000 (Hering et al., 2010). The WFD is a long-term sustainable water management plan based on the overall goal of protecting the aquatic environment (Kallis and Butler, 2001). In article 4 of the WFD, the general objective to be attained is that all surface water and groundwater should achieve good status by 2015. In addition, normative definitions for environmental objectives are described in detail. However, development of specific numerical criteria and classification schemes including class boundaries is only described in general. Taking the results of the inter-calibration exercise into account, member states are obligated to set detailed values for defining the status for each water body. Notably, the WFD provides a set of conditions needed for allowing a number of exemptions to the general goals such as less stringent objectives, extension of deadline beyond 2015, or implementation of new projects.

\subsection{Japan}

Japan, as the first country to do so, released its environmental quality criteria for water pollution and national effluent criteria in 1971 based on the Basic Environmental Law (Nakanishi, 2016). The criteria were divided into two kinds of standards for protecting human health and for the living environment. Each type of standard establishes levels desirable for achieving and maintaining public water and other water-quality policy objectives. Environmental standards were established for groundwater quality in March, 1997. Since then, a complete water environment protection standard for public water and groundwater has been created. When it comes to public water quality protection, common policies for ordinary water areas and specific policies for protecting closed water areas, such as lakes, the Inland Sea, Ariake Sea, and Yatsushiro Sea, were respectively carried out. Additional environmental quality standards were established step by step in recent years in Japan. For example, environmental quality criteria for total zinc to conserve aquatic life were implemented in 2003.

The Ministry of Environment ensures that environmental policy is at the heart of government decision-making. However, unified national WESs provide the application range for applicable industries and facilities without considering industry differences. For the industries having difficulty in achieving the unified standards, looser tentative standards could be implemented, which would be gradually tightened to implement a unified standard. The local government, for example prefecture, has the right to promulgate more stringent local environmental standards for the public water to replace the unified standards. For non-specific institutions, the governments of the prefectures, and even the towns, could establish local WESs to limit emission without submitting local WESs to the Ministry of the Environment for recording. In general, Japan's local government at all levels has a strong initiative to establish and implement stricter local WESs according to its local environmental conditions. 


\section{Present situations of WQC and WESs in China}

\subsection{WQC and WESs system}

China's WES system consists of standards on water environment quality, water pollution emission, and monitoring methods at national and local levels. However, no WQC are released or recommended by the government. Although Chinese scientists have conducted some case studies on WQC in China (Jin et al., 2009; Lei et al., 2009; Yan et al., 2010), these studies are not sufficient for establishing WESs since their methods are not unified. After comparing WQC and WESs developed by China with those in other developed countries (Table 1), three limitations of the current WES system in China were revealed as follows:

\section{(1) Lack of national guidelines}

The primary reason why pre-existing case studies of WQC in China cannot be used in developing WESs is that the methods used in the studies were different from each other. Therefore, their results are not comparable. As China has commenced its own criteria strategy, priority should be given in establishing a national process for developing guidelines and recommended methods for establishing WQC.

(2) Lack of policy guarantees of WQC as the scientific basis for WESs

Because China does not have its own WQC, current policies cannot provide a clear description of the scientific basis for WESs. As a part of the criteria strategy, it is necessary to implement policy guarantees that WQC will be the scientific basis for developing WESs in the water environmental management system.

(3) National unified WESs might not be suitable for all water bodies in China

Considering the diversity of natural and social conditions in different regions, national unified WESs might not be appropriate for all the water bodies in China. For example, industrial structures can vary significantly in different regions of China, which results in different pollutant emission fluxes and disparate water environment protection targets. Therefore, the national unified WESs cannot function well in all the water environmental management systems.

Although a series of policies exist to guarantee public participation when establishing WESs, there still a long road ahead for government to actually implement public participation. For example, public opinions and consulting drafts are required before new standards are released, and public environmental information should be disclosed on government web sites or other places that open to the public. However, most of these policies have not yet been implemented, especially by local government.

\subsection{Governance status quo}

Usually, there are legal norms between WQC and WESs in developed countries. For example, the Clean Water Act of the USA authorizes the US EPA to develop WQC and requires states and tribes to establish their own water quality standards by adopting or revising the WQC recommended by the US EPA. The situation in China is different. The State Environmental Protection Administration (SEPA) of China issued Approaches for Environmental Standards Management in 1999, and the

\begin{tabular}{|c|c|c|c|c|c|}
\hline Region & $\begin{array}{l}\text { WQC } \\
\text { provider }\end{array}$ & $\begin{array}{l}\text { Relationship of } \\
\text { WQC and WESs }\end{array}$ & Establishing of WESs & Developed countries & China \\
\hline USA & US EPA & $\begin{array}{l}\text { WQC provide scientific } \\
\text { basis for WESs, } \\
\text { especially water quality } \\
\text { standards }\end{array}$ & $\begin{array}{l}\text { States and tribes are responsible } \\
\text { for establishing their own WESs } \\
\text { based on recommended national } \\
\text { WQC }\end{array}$ & \multirow{5}{*}{$\begin{array}{l}\text { 1. Recommended national } \\
\text { WQC (guidelines) are } \\
\text { available; } \\
\text { 2. WQC provide scientific } \\
\text { basis for WESs; } \\
\text { 3. Regional governments are } \\
\text { responsible for establishing } \\
\text { WESs or stricter local } \\
\text { environmental standards. }\end{array}$} & \multirow{5}{*}{$\begin{array}{l}\text { 1. No recommended } \\
\text { national WQC yet; } \\
\text { 2. Current WESs are } \\
\text { derived based on WQC or } \\
\text { water quality standards } \\
\text { in developed countries; } \\
\text { 3. WESs are nationally } \\
\text { unified. }\end{array}$} \\
\hline Australia & $\begin{array}{l}\text { ANZECC \& } \\
\text { ARMCANZ }\end{array}$ & $\begin{array}{l}\text { WQC (guidelines) } \\
\text { provide scientific basis } \\
\text { for WESs }\end{array}$ & $\begin{array}{l}\text { States and territories are } \\
\text { responsible for establishing } \\
\text { water quality objectives based } \\
\text { on national guidelines }\end{array}$ & & \\
\hline EU & $\begin{array}{l}\text { European } \\
\text { Environment } \\
\text { Agency }\end{array}$ & $\begin{array}{l}\text { WQC (guidelines) } \\
\text { provide scientific basis } \\
\text { for WESs }\end{array}$ & $\begin{array}{l}\text { Member states are obliged to } \\
\text { establish detailed water quality } \\
\text { objectives based on EU guidelines }\end{array}$ & & \\
\hline Japan & $\begin{array}{l}\text { Ministry of the } \\
\text { Environment }\end{array}$ & $\begin{array}{l}\text { WQC (guidelines) } \\
\text { provide scientific basis } \\
\text { for WESs }\end{array}$ & $\begin{array}{l}\text { Prefectures and towns are } \\
\text { responsible for establishing } \\
\text { stricter local water environment } \\
\text { standards based on the national } \\
\text { unified WQC }\end{array}$ & & \\
\hline China & No & $\begin{array}{l}\text { WESs, especially water } \\
\text { quality standards, are } \\
\text { derived based on WQC } \\
\text { in other countries }\end{array}$ & $\begin{array}{l}\text { Water quality standards are } \\
\text { nationally unified }\end{array}$ & & \\
\hline
\end{tabular}

WESs: water environment standards; WQC: water quality criteria; US EPA: US Environmental Protection Agency; ANZECC: Australian and New Zealand Environment Conservation Council; ARMCANZ: Agriculture and Resource Management Council of Australia and New Zealand. 
Approaches for Management of Revision of National Environmental Standards in 2006. Since China had not yet released national WQC at that time, the term "water quality criteria" did not appear in these two normative documents. However, a significant increase in the status of results from scientific research can be found in the version of 2006. For instance, in terms of principles for revising environmental standards, the 2006 document added the following statements on the basis of the 1999 document:

(1) Environmental standards should adapt to the levels of economic and technological development, be scientifically sound and practical, and promote improvement of environmental quality.

(2) Environmental standards should be released based on the results of scientific research and practical experience. The content of environmental standards should be scientifically sound, reasonable and feasible.

Although specific guidance on how the statements could play their roles in developing the environmental standards is lacking, they still provided a general description of the current status of scientific research. As China has already commenced on its own environmental criteria strategy, scientific research on relevant policies should also be taken into consideration.

\section{Feasibility of local-standard-based WESs in China}

Considering the geographic, regional, eco-environmental and socio-economic diversity in China, establishing a localstandard-based WES system might be more suitable for the country. Nevertheless, scientific research on WQC and WESs usually requires large amounts of money and long periods of time. In the present study, the data of regional GDP, GDP per capita, and residential consumption of urban and rural areas were collected to reflect the level of economic development; the data on number of universities, research and development (R\&D) personnel population, environmental practitioners and patents were collected to reflect the capability of scientific support; and the number of water-relevant standards and environmental standards was collected to reflect the policy environment. Through analyzing these three basic conditions in China, we analyzed the feasibility of establishing a localstandard-based WES system.

\subsection{Economic development}

Since establishing environmental policy is closely linked to the level of regional economic development, four indicators, including regional GDP, GDP per capita, urban resident consumption and rural resident consumption in 2014, were compared among the 31 provinces in mainland China (Fig. 3). Greater economic development and activity could provide better economic foundations and assurances for formulating and implementing WQC and WESs. Moreover, with the improvement of people's living conditions, people will tend to have higher expectations for environmental quality, which will force governments to increase investment to protect the environment in both the short-term and the long-term. According to Fig. 3, three aspects are worth noting: (a) The GDPs of coastal provinces in eastern China were greater than those of the western and inland provinces. Guangdong (\$1090.79 billion), Jiangsu (\$1047.01 billion) and Shandong ( $\$ 955.93$ billion) were the top three, while Tibet ( $\$ 14.81$ billion),

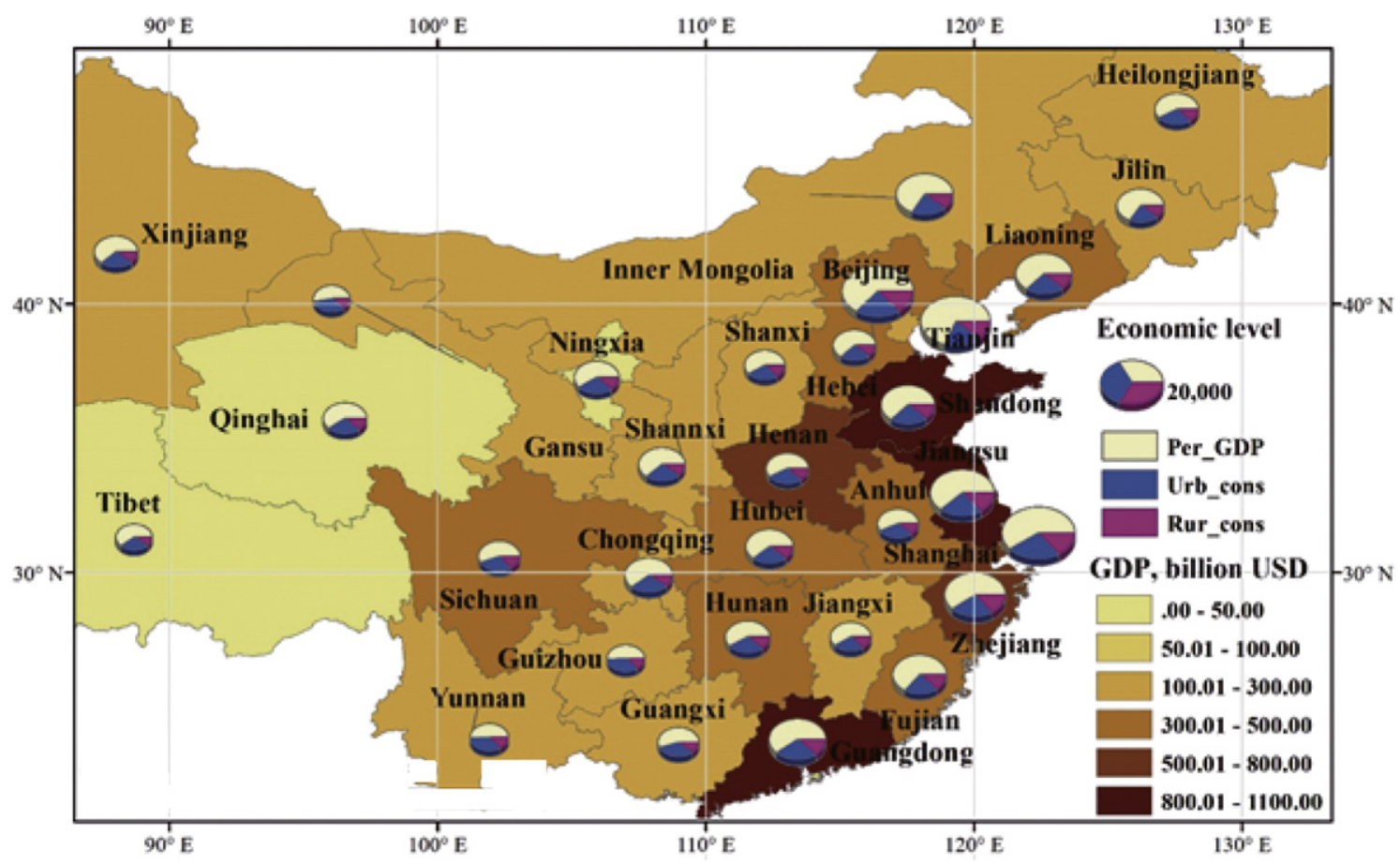

Fig. 3 - Economic development levels of mainland China. 
Qinghai ( $\$ 37.05$ billion) and Ningxia ( $\$ 44.27$ billion) ranked the lowest three. The phenomenon of unbalanced economic development between eastern and western China still exists. Overall, the economic development of the eastern regions of China was greater than those of western regions; (b) The sums of GDP per capita and urban and rural resident consumption among the 31 provinces were represented as pie charts for comparison. Shanghai, Beijing and Tianjin ranked the highest, with GDP per capita $\$ 15,663, \$ 16,085$, and $\$ 16,927$, respectively. However, when compared with developed countries, economic development in China still fell short. According to the report of the International Monetary Fund, the national average GDP per capita of the USA, Canada and Australia in 2014 was $\$ 54,597, \$ 50,398$ and $\$ 61,219$, respectively; (c) Provinces with large GDPs were not the ones with top GDP per capita, and vice versa. For example, the three provinces with the greatest GDP (Guangdong, Jiangsu and Shandong) ranked 9th, 4th and 10th when comparing their GDPs per capita. The three provinces with greatest GDPs per capita (Tianjin, Beijing and Shanghai) ranked 17th, 13th and 12th when comparing their GDPs.

\subsection{Scientific support capability}

Scientific support is usually provided by universities, environmental practitioners and $R \& D$ researchers and measured by the number of authorized invention patents. However, the number of granted patents might not be the best indicator of scientific output or impact on environmental quality in an area. In the present study, the number of authorized invention patents in each province, which was used as an indicator of the overall regional science and engineering infrastructure and strength of innovation, was chosen as one significant indication of scientific support capability. Data on the number of universities, $R \& D$ researchers and environmental practitioners in each province were collected from the national statistical yearbook and used to construct the pie charts shown in Fig. 4.

There was an uneven geographical distribution of the numbers of authorized invention patents in China. In general, the numbers of patents in the eastern and central provinces were comparatively larger. The largest number, which appeared in Beijing, was as high as 23,237 . The numbers of universities, thousands of R\&D researchers and thousands of environmental practitioners were compared. Beijing, Guangdong and Jiangsu ranked the top three, indicating that the potential scientific research power was strong there. This trend was approximately consistent with the distribution of economic development intensity. However, it was remarkable that the proportions of the population that are environmental practitioners and $R \& D$ researchers in each province (the total number is 31) were different from that trend. Beijing, Guangdong and Jiangsu (5.54\%, 18.04\%, and 23.20\%, respectively) ranked 31st, 26th, and 20th, respectively. They were all less than average (26.34\%), while Ningxia (50.35\%), Inner Mongolia (44.37\%) and Jiangxi (42.78\%) ranked the top three. Although the total population of environmental practitioners was small in Ningxia, Inner Mongolia and Jiangxi (7100, 27,600 and 23,700, respectively), the larger proportions in these provinces also indicated that the local governments paid close attention to protecting the environment.

\subsection{Policy environment}

The Water Pollution Control Act of China authorized the State Environment Protection Ministry (SEPM) to develop national

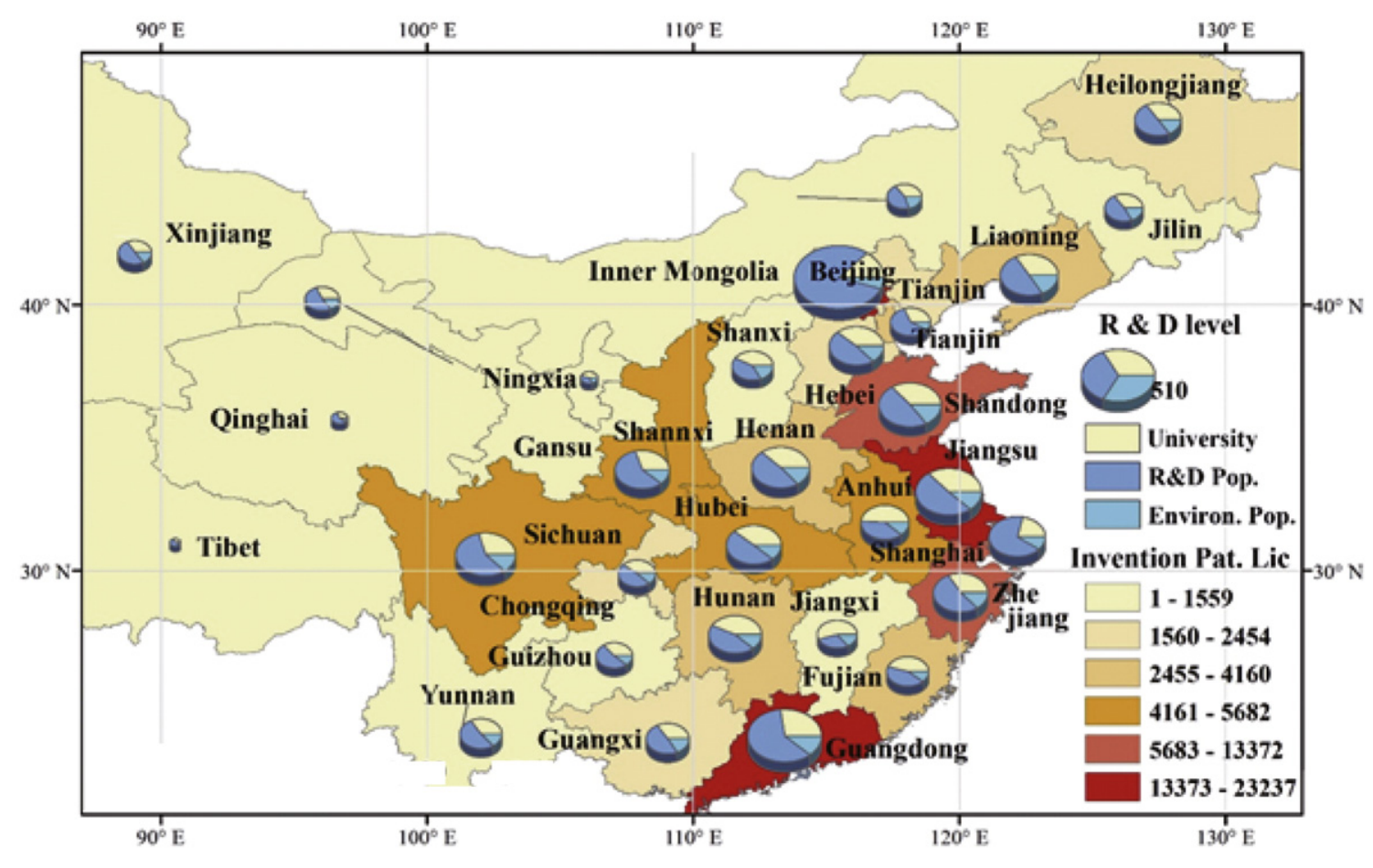

Fig. 4 - Research and development level in each of 31 provinces of mainland China. 
WESs. Provinces could develop local standards for items that were not provided in the national water quality standards. Local standards should be submitted to the SEPM for the record. In the present study, in order to bring policy data into correspondence with the data above, 282 local environmental standards and 94 local water standards, almost all of which were published before 2015, were collected. All the promulgated local environmental standards were either pollutant emission standards or standards for pollutant monitoring, which indicated that no province had developed local WESs without authorization. The numbers of local environmental standards and water-relevant standards in each province were compared (Fig. 5). Among all the 31 provinces, no local environmental standards were promulgated in Inner Mongolia, Anhui, Hubei and Tibet, while Beijing, Shandong, Hebei and Guangdong promulgated the most local environmental standards, with the numbers of 47, 42, 20 and 20, respectively. According to the above results, the numbers of local environmental standards promulgated in provinces depended on the local economic development and capability of scientific support. In fact, the provinces with more water-relevant standards were suffering more severe water pollution as well as scarcity of water resources. The number of local environmental standards and water-relevant standards could be regarded as an indirect reflection of the policy environment for WESs. In other words, governments that promulgate more local environmental standards and water-relevant standards might be more supportive to the development of their own WESs.

Considering the current economic development, scientific support capability and policy environment, China is still not ready to implement local-standard-based WESs nationwide. The economic development, scientific support capability and policy environment are quite different among the 31 provinces. Some provinces might have neither financial nor institutional capability to develop or establish appropriate local-standard-based WESs. Scientific research is also a very important factor for establishing WESs. Without adequate scientific research, the WESs would never be developed. As the analysis above shows, it was obvious that scientific support capability was uneven across provinces. Both the national and local government should provide financial support and favorable policies for scientific research. Although for some period of time, a national unified WES system will remain dominant in China, establishing local-standard-based WESs could be promoted in those provinces with relatively suitable conditions (such as the Beijing-Tianjin-Hebei region, Guangdong province and Shanghai-Jiangsu-Zhejiang region). As soon as the pilot projects for local-standard-based WESs are successfully implemented in one or more provinces, valuable experience could be shared and spread to other provinces to enable them to attempt to implement their own local-standard-based WESs. As a consequence, the WES system of China could be promoted and developed rapidly.

\section{Mechanism for deriving WESs from WQC in China}

China is not comprehensively ready to replace its present national unified WESs with the new local-standard-based WESs. A mechanism framework of functional responsibility, policy guarantee and transformation process for deriving WESs from WQC in China was developed (Fig. 6).

\subsection{Functional responsibility}

Functional responsibility includes two levels: the national level and the regional level. The SEPM, in the Chinese central government, is responsible for organizing and supervising

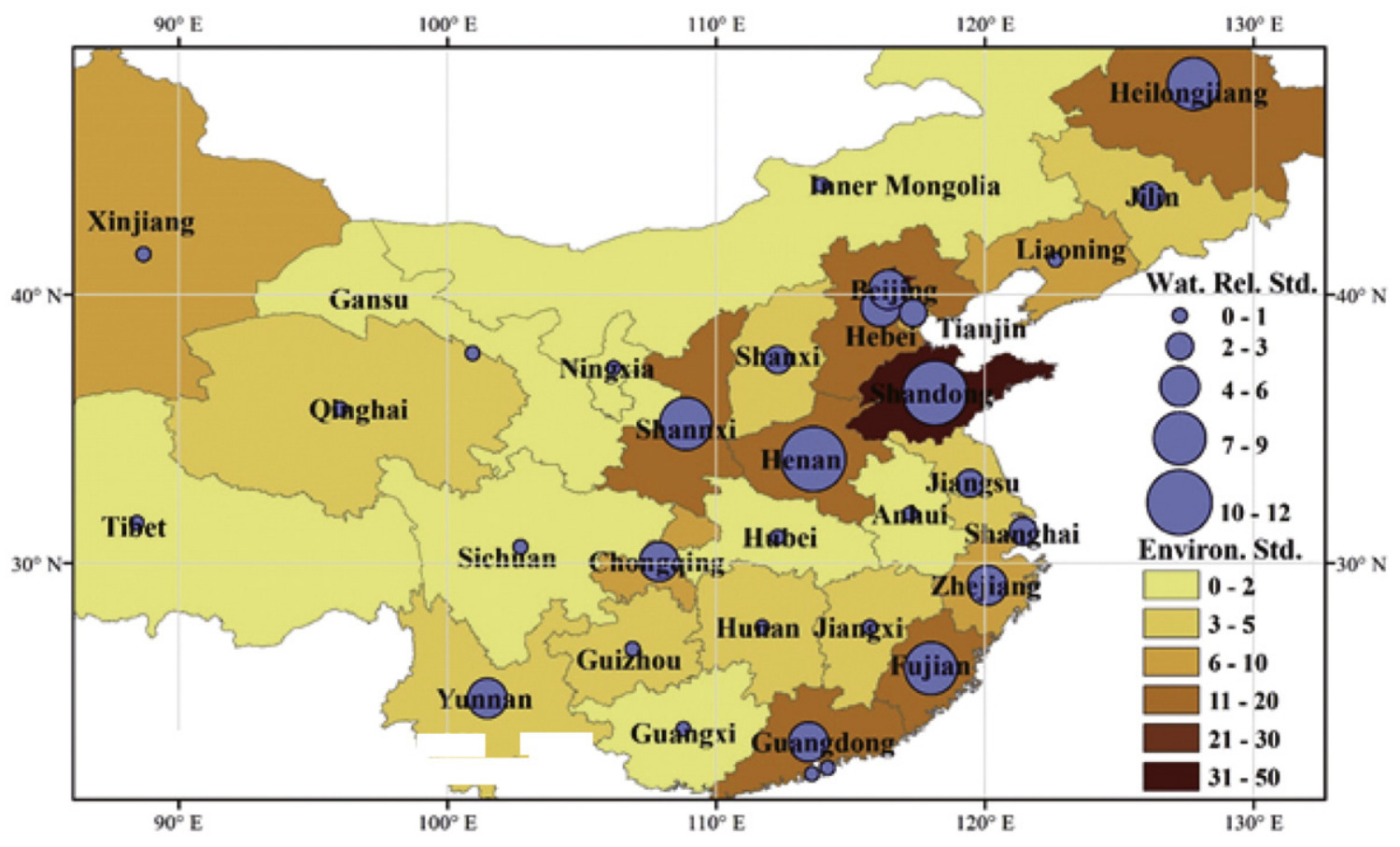

Fig. 5 - Number of water-relevant and environmental standards in mainland China. 

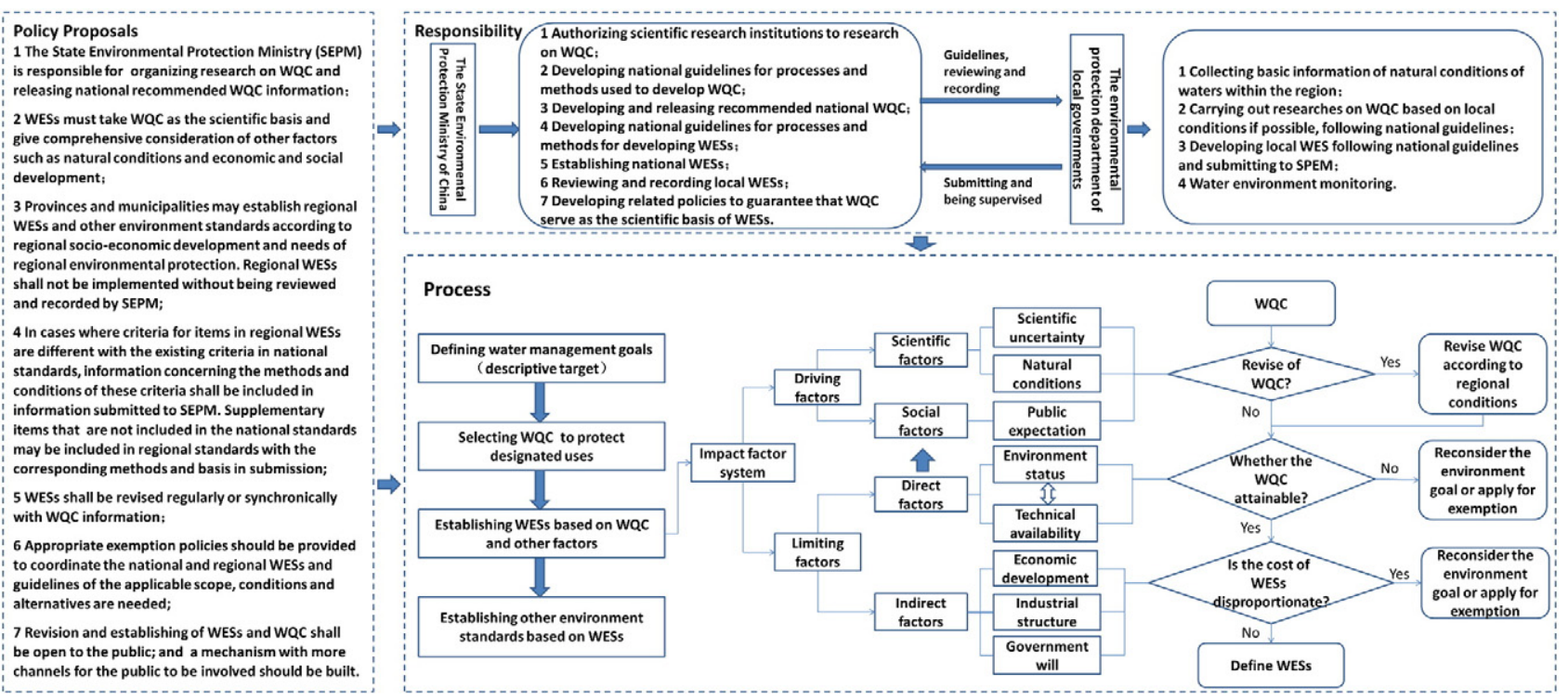

Fig. 6 - Framework of mechanism for deriving WESs from WQC in China.

research and development of WQC and establishing WESs. More specifically, SEPM is responsible for:

(1) authorizing scientific research institutions to carry out research on WQC; (2) developing national guidelines for processes and methods used to develop WQC; (3) developing and releasing recommended national WQC; (4) developing national guidelines for processes and methods for developing WESs; (5) establishing national WESs; (6) reviewing and recording local WESs; (7) developing related policies to guarantee that WQC serve as the scientific basis of WESs.

Due to the fact that research and development of WQC requires a large amount of human, material and financial resources and that the guidelines for deriving WESs from WQC in China are not available, provinces will play the primary role in developing WQC and establishing WESs, over a relatively long period of time. Nevertheless, local governments should participate in more research to establish WQC and WESs. Environmental protection departments of local governments should be responsible for collecting basic information on the natural conditions of waters within the region and carry out research on WQC based on local conditions. If possible, they should be required to monitor aquatic environments, develop local WESs through national guidelines and submit WESs to SPEM.

\subsection{Transformation process}

This part is the core of the mechanism framework. Generally, the process comprises four steps: (1) defining water management goals (descriptive target); (2) selecting WQC to protect designated uses; (3) establishing WESs based on WQC and other factors; and (4) establishing other environmental standards based on WESs. Of these, this study mainly focused on the third step, i.e., the factors that might affect deriving WESs based on WQC. According to the results of previous studies and the current situation in China, an impact factor system was established.

\subsubsection{Driving factors}

In principle, setting of standards should be viewed from the perspective of decision-making under uncertainty, involving the interplay between scientific basis and public opinions. Determination of designated uses should reflect social values and selection of criteria should largely be based on scientific aspects. However, determination of criteria associated with attainment-nonattainment transition ideally requires the integration of both scientific basis and social values. Natural variability and scientific uncertainty in designated uses imply that selection of a criterion with $100 \%$ assurance of use attainment is generally unrealistic. Accordingly, scientific uncertainty and attitude toward the risk of nonattainment should be parts of the standard level decision (Reckhow et al., 2005). Therefore, WQC need to be revised when WESs are established.

\subsubsection{Limiting factors}

Current environmental status and technical availability are the primary factors that restrict the development of WESs. If WQC selected for designated uses are not attainable, the water environmental management goal should be reconsidered or an exemption policy that allows for less stringent objectives should be applied. Meanwhile, economic development, industrial structure and the government's will could also indirectly affect establishment of WESs.

\subsubsection{Policy proposal}

In order to guarantee the scientific basis status of WQC and WESs and the smooth running of the mechanism, seven suggestions are made: (1) The SEPM is responsible for organizing research on WQC and releasing recommended national WQC information; (2) WESs must take WQC as the scientific basis and give comprehensive consideration of other factors such as natural conditions and economic and social development; (3) Provinces and municipalities may establish regional WESs and other environmental standards 
according to regional socio-economic development and the needs of regional environmental protection. Regional WESs shall not be implemented without being reviewed and recorded by SEPM; (4) In cases where criteria for items in regional WESs are different from the existing criteria in the national standards, information concerning the methods and conditions of these criteria shall be included and submitted to SEPM. Supplementary items that are not included in the national standards may be included in regional standards with the corresponding methods and the scientific basis submitted to SPEM; (5) WESs shall be revised regularly or synchronously with WQC information; (6) Appropriate exemption policies should be provided to coordinate the national and regional WESs and the guidelines for the applicable scope, conditions and alternatives as needed; (7) Revision and establishment of WESs and WQC shall be open to the public and a mechanism with more channels for the public to be involved should be built.

In general, SEPM is responsible for establishing WQC, while the governments of provinces and municipalities can establish local WESs and other environmental standards according to the specific conditions of nature and regional socio-economic development. The local WESs and other environmental standards shall not be implemented without the approval of SEPM. Governments should revise WESs regularly or synchronously with WQC information and with supervision or suggestions from the public.

\section{Conclusions}

Analysis of the current WESs in China and comparisons of WESs with those in developed countries revealed several limitations, including: 1) the goal of WESs in China was to protect the uses of water resources rather than human health, which made it hard to transform WQC to WESs, and national guidelines were lacking for establishing WQC; 2) scientific and rational policy guarantees for transforming WQC to WESs were insufficient in the current environment management system in China; 3) the national unified WESs were not adapted to the diversity of natural environments and socio-economic development in China. With the development of recent decades, a relatively complete WES system has been built in China. Further improvements are still needed in terms of the scientific feasibility of WESs. A framework for transforming WQC to WESs in China was proposed, which involves the state environmental protection department, local environmental protection department, and WESs and WQC research. However, analysis of the conditions for transformation from WQC to WESs in China showed a serious imbalance in terms of both economic development and scientific support capacity.

Sustainable management of water resources requires careful prioritization of available information and research on WQC and WESs, and focuses on the efforts to optimize the decisions that take environmental, economic, and societal aspects into consideration simultaneously. The proposed framework can serve as a flexible transformation flowchart for future decision support and can be a step toward more sustainable decision-making for WQC-related studies and water management. Accomplishment of these goals will undoubtedly play a significant role in the development of local WQC, environmental protection and management not only in China, but also all over the world.

\section{Acknowledgments}

This work was supported by the National Water Pollution Control and Treatment Science and Technology Major Project (No. 2015ZX07203-005) and the National Natural Science Foundation of China (No. 41571478).

\section{R EFEREN C E S}

Chen, Y., Yu, S.Y., Song, T., Li, Y.B., Liu, H.L., Zhang, X.H., Su, G.Y., Li, B., Yu, H.X., Giesy, J.P., 2016. Site-specific water quality criteria for aquatic ecosystems: a case study of pentachlorophenol for Tai Lake, China. Sci. Total Environ. 541, 65-73.

Chèvre, N., Loepfe, C., Singer, H., Stamm, C., Fenner, K., Escher, B.I., 2006. Including mixtures in the determination of water quality criteria for herbicides in surface water. Environ. Sci. Technol. 40 (2), 426-435.

Deland, M.R., 1979. Regulatory alert: water quality criteria for toxics. Environ. Sci. Technol. 13 (6), 648.

Feng, C.L., Wu, F.C., Zheng, B.H., Meng, W., Paquin, P.R., Wu, K.B., 2012. Biotic ligand models for metals-a practical application in the revision of water quality standards in China. Environ. Sci. Technol. 46 (20), 10877-10878.

Fu, B.J., Zhuang, X.L., Jiang, G.B., Shi, J.B., Lu, Y.H., 2007. FEATURE: environmental problems and challenges in China. Environ. Sci. Technol. 41 (22), 7597-7602.

Hering, D., Borja, A., Carstensen, J., Carvalho, L., Elliott, M., Feld, C.K., Heiskanen, A.S., Johnson, R.K., Moe, J., Pont, D., Solheim, A.L., Bund, W.V.D., 2010. The European water framework directive at the age of 10: a critical review of the achievements with recommendations for the future. Sci. Total Environ. 408 (19), 4007-4019.

Jin, X.W., Lei, B.L., Xu, Y.P., Zha, J.M., Wang, Z.J., 2009. Methodologies for deriving water quality criteria to protect aquatic life (ALC) and proposal for development of ALC in China: a review. Asian J. Ecotoxicol. 4 (5), 609-616.

Jin, X.W., Wang, Y.Y., Giesy, J.P., Richardson, K.L., Wang, Z.J., 2014. Development of aquatic life criteria in China: viewpoint on the challenge. Environ. Sci. Pollut. Res. 21, 61-66.

Kallis, G., Butler, D., 2001. The EU water framework directive: measures and implications. Water Policy. 3 (2), 125-142.

Kassem, M.A., Kassem, A.A., Ammar, H.O., 1969. On heavy metal ions contamination from ampoule glass. Pharm. Acta Helv. 44 (9), 535-540.

Lei, B.L., Jin, X.W., Huang, S.B., 2009. Discussion of quality criteria for three chlorophenols in Taihu Lake. Asian J. Ecotoxicol. 4 (1), 40-49.

Meng, W., Yan, Z.G., Liu, Z.T., 2009. Analysis of guidelines for deriving water quality criteria in the United States and construction of related criteria in China. Res. Environ. Sci. 22 (7), 757-761.

Meng, W., Zhang, Y., Zheng, B., 2006. The quality criteria, standards of water environment and the water pollutant control strategy on watershed. Res. Environ. Sci. 19 (3), 1-6.

Nakanishi, Y., 2016. Introduction: the impact of the International and European Union Environmental Law on Janpanese Basic Environmental Law. In: Nakanishi, Y. (Ed.), Contemporary Issues in Environmental Law: the EU and Japan. Springer, Berlin, pp. 1-14.

Reckhow, K.H., Arhonditsis, G.B., Kenney, M.A., Hauser, L., Tribo, J., Wu, C., Elcock, K.J., Steinberg, L.J., Stow, C.A., Mcbride, S.J., 
2005. A predictive approach to nutrient criteria. Environ. Sci. Technol. 39 (9), 2913-2919.

Russo, R.C., 2002. Development of marine water quality criteria for the USA. Mar. Pollut. Bull. 45 (1-12), 84-91.

Shaw, W.H.R., Grushkin, B., 1957. The toxicity of metal ions to aquatic organisms. Arch. Biochem. Biophys. 67 (2), 447-452.

Stephan, C.E., 2002. Use of speices sensitivity distributions in the derivation of water quality criteria for aquatic life by the U.S. Environmental Protection Agency. In: Posthuma, L., Suter II, G.W., Traas, T.P. (Eds.), Species Sensitivity Distributions in Ecotoxicology. Lewis publishers, Boca Raton, pp. 211-220.

Wang, S.X., Hao, J.M., 2012. Air quality management in China: issues, challenges, and options. J. Environ. Sci. 24 (1), 2-13.

Wang, Y., Wu, F.C., Mu, Y.S., Zeng, E.Y., Meng, W., Zhao, X.L., et al., 2016. Directly predicting water quality criteria from physicochemical properties of transition metals. Sci. Rep. 6, 22515

Wang, X., Zou, Z., Zou, H., 2013. Water quality evaluation of Haihe River with fuzzy similarity measure methods. J. Environ. Sci. 25 (10), 2041-2046.
Wu, F.C., Meng, W., Zhao, X.L., Li, H.X., Zhang, R.Q., Cao, Y.J., et al., 2010. China embarking on development of its own national water quality criteria system. Environ. Sci. Technol. 44 (21), 7992-7993.

Yan, Z.G., Meng, W., Liu, Z.T., Yu, R.Z., Wang, H., 2010. Development of aquatic criteria for cadmium for typical basins in China. Res. Environ. Sci. 23 (10), 1221-1228.

Yan, Z.G., Wu, J.Y., Wang, X.N., Zhang, Y.H., 2015. Development of water quality criteria for toxic organic pollutants. In: Yan, Z.G., Liu, Z.T. (Eds.), Toxic Pollutants in China Study of Water Quality Criteria. Springer, Berlin, pp. 1-56.

Yang, S., Yan, Z.G., Xu, F.F., Wang, S.R., Wu, F.C., 2012. Development of freshwater aquatic life criteria for Tetrabromobisphenol A in China. Environ. Pollut. 169 (15), 59-63.

Zhang, L., He, G.Z., Mol, A.P.J., Lu, Y.L., 2013. Public perceptions of environmental risk in China. J. Risk Res. 16 (2), 195-209.

Zhang, T., Zhu, H.L., Jin, H.J., 1998. Deriving freshwater quality criteria of sulphocyanic sodium for the protection of aquatic life in China. J. Environ. Sci. 10 (2), 151-158. 